\title{
Mitochondrial DNA depletion in prostate epithelial cells promotes anoikis resistance and invasion through activation of PI3K/Akt2
}

\author{
L Moro*, ${ }^{*,}$ AA Arbini' ${ }^{2}$, JL Yao ${ }^{3}$ PA di Sant'Agnese ${ }^{3}$, E Marra ${ }^{1}$ and M Greco ${ }^{1}$
}

Neoplastic transformation of prostate epithelium involves aberrant activation of anti-apoptotic and pro-invasive pathways triggered by multiple poorly understood genetic events. We demonstrated earlier that depletion of mitochondrial DNA (mtDNA) induces prostate cancer progression. Here, using normal prostate epithelial PNT1A cells we demonstrate that mtDNA depletion prevents detachment-induced apoptosis (anoikis) and promotes migratory capabilities onto basement membrane proteins through upregulation of p85 and p110 phosphatidylinositol 3-kinase (PI3K) subunits, which results in Akt2 activation and phosphorylation of downstream substrates GSK3 $\beta$, c-Myc, MMP-9, Mdm2, and p53. Pharmacological or genetic PI3K inhibition, siRNA-mediated Akt2 depletion, as well as mtDNA reconstitution were sufficient to restore sensitivity to anoikis and curtail cell migration. Moreover, Akt2 activation induced glucose transporter 1 (GLUT1) expression, glucose uptake, and lactate production, common phenotypic changes seen in neoplastic cells. In keeping with these findings, several prostate carcinoma cell lines displayed reduced mtDNA content and increased PI3K/Akt2 levels when compared to normal PNT1A cells, and Akt2 downregulation prevented their survival, migration and glycolytic metabolism. On a tissue microarray, we also found a statistically significant decrease in mtDNA-encoded cytochrome oxidase I in prostate carcinomas. Taken together, these results provide novel mechanistic evidence supporting the notion that mtDNA mutations may confer survival and migratory advantage to prostate cancer cells through Akt2 signaling.

Cell Death and Differentiation (2009) 16, 571-583; doi:10.1038/cdd.2008.178; published online 12 December 2008

Mitochondria are complex intracellular organelles involved in vital cellular tasks such as energy production, reactive oxygen species generation and apoptosis, all of which have been postulated to play a role in the initiation or perpetuation of the malignant phenotype. ${ }^{1}$ They are endowed with their own genome consisting of a $16.6 \mathrm{~kb}$ circular DNA (mtDNA) that encodes for two rRNAs, 22 tRNAs, and 13 polypeptides of the respiratory chain including the main catalytic subunit of complex IV, cytochrome oxidase I (Cox I). Growing evidence suggests that mtDNA mutations may be associated with tumor development and progression in a variety of cancers, including prostate carcinoma., ${ }^{2,3}$ For instance, it has been reported that introduction of a pathogenic mtDNA ATPase 6 mutation into the PC-3 prostate cell line results in increased tumor growth, ${ }^{2}$ and that the inheritance of mitochondrial haplotype $U$ is associated with increased risk of prostate cancer in white Americans, ${ }^{4}$ thus implicating mtDNA in prostate cancer etiology. However, despite all this new evidence, the molecular mechanisms linking mtDNA mutations and prostate cancer remain largely obscure.
The main experimental strategy employed to study the contribution of mtDNA mutations in cancer relies upon the high sensitivity of mtDNA to low concentrations of ethidium bromide (EtBr), which inhibits mtDNA replication and transcription thus inducing mtDNA depletion without affecting the nuclear DNA. ${ }^{5}$ Using this technique, Avadhani and co-workers have demonstrated that transient mtDNA depletion promotes invasive behavior, as well as decreased drug-induced apoptosis in C2C12 myoblasts and A549 lung carcinoma cells. ${ }^{6,7}$ We and others have previously documented that mtDNA depletion in LNCaP androgen-dependent prostate carcinoma cells induces progression to androgenindependence with increased cell migration and resistance to common chemotherapeutic agents. ${ }^{8,9}$

Epithelial cells normally undergo apoptosis after loosing contact with matrix ligands for integrins, a cell detachmentinduced apoptosis known as 'anoikis'. ${ }^{10}$ Anoikis prevents detached epithelial cells from thriving, thus is essential for maintaining tissue architecture. The ability of cells to survive under anchorage-independent conditions is a hallmark of neoplastic transformation ${ }^{10}$ that is directly related to their

\footnotetext{
${ }^{1}$ Institute of Biomembranes and Bioenergetics, National Research Council (CNR), Bari 70126, Italy; ${ }^{2}$ Department of Pathology, UT Southwestern Medical Center, Dallas, TX 75390, USA and ${ }^{3}$ Department of Pathology and Laboratory Medicine, University of Rochester School of Medicine and Dentistry, Rochester, NY 14642, USA ${ }^{*}$ Corresponding author: L Moro, Institute of Biomembranes and Bioenergetics, National Research Council (CNR), Via Amendola 165/A, 70126 Bari, Italy. Tel: + 39080544 2412; Fax: + 39080544 3317; E-mail: I.moro@ ibbe.cnr.it

Keywords: mitochondrial DNA; PI3K; Akt2; anoikis; prostate cancer

Abbreviations: BPH, benign prostatic hyperplasia; DNp85, dominant-negative p85; EtBr, ethidium bromide; FBS, fetal bovine serum; GAPDH, glyceraldehyde 3-phosphate dehydrogenase; GSK3 $\beta$, glycogen synthase kinase 3 $\beta$; HGCA, high-grade prostate carcinoma; LGCA, low-grade prostate carcinoma; LN-1, laminin-1; Mdm2, murine double minute; MMP-9, matrix metalloproteinase-9; mtDNA, mitochondrial DNA; PARP, poly (ADP-ribose) polymerase; PI3K, phosphatidylinositol 3-kinase; PIN, prostatic intraepithelial neoplasia

Received 26.5.08; revised 20.10.08; accepted 07.11.08; Edited by DR Green; published online 12.12.08
} 
metastatic potential. ${ }^{11}$ In this study, we explored the effect of mtDNA depletion upon anoikis sensitivity and invasion using mtDNA-depleted PNT1A prostate cells as a model. We demonstrate that mtDNA depletion is sufficient to induce anoikis resistance and promote cell motility through activation of phosphatidylinositol 3-kinase (PI3K)/Akt2 signaling. Furthermore, we demonstrate that mtDNA depletion is common among several prostate carcinoma cell lines and mtDNA alterations are also present in human prostate carcinoma samples in vivo.

\section{Results}

Depletion of mtDNA in PNT1A cells. We chose the immortalized human prostate epithelial cell line PNT1A as a model to explore the role of mtDNA mutations in prostate malignant progression. PNT1A are non-tumorigenic cells ${ }^{12}$ that exhibit molecular and biochemical properties close to normal prostate epithelium, ${ }^{13-16}$ albeit they may be considered preneoplastic as they have suffered an initial genetic hit (expression of SV40T for immortalization) that renders them susceptible to progression towards malignant transformation. Long-term cell exposure to low concentration of $\mathrm{EtBr}$ selectively reduces the mtDNA content in numerous cell types, and this effect is reversible after $\mathrm{EtBr}$ removal from the culture medium. Using this technique, we generated mtDNA-depleted PNT1A cells that were auxotrophic for uridine and pyruvate, as previously reported with other cell types. ${ }^{6,17}$ To confirm mtDNA depletion in EtBr-treated cells, we performed conventional and real-time PCR with specific primers targeting different mtDNA regions. As shown in Figure $1 \mathrm{a}, \mathrm{EtBr}$ treatment resulted in $>70 \%$ reduction of PCR products for Cox I, Cox II, D-loop and NADH dehydrogenase 6 (ND6), and removal of $\mathrm{EtBr}$ restored the mtDNA content to $75 \%$ of normal within 15 days (reverted cells). Southern blotting analysis with a mtDNA-specific probe confirmed an $85 \% \pm 8$ reduction in mtDNA levels compared a
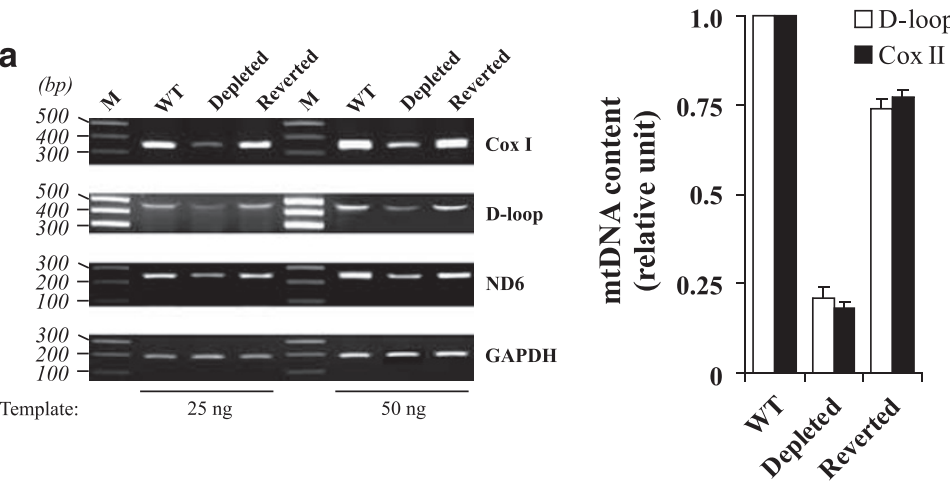

b

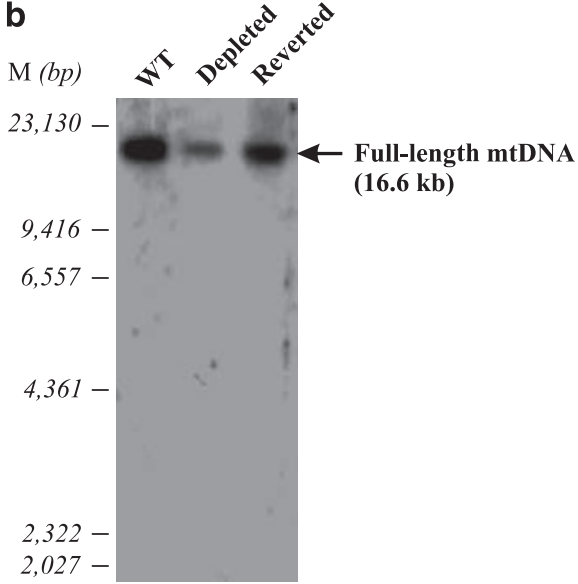

c

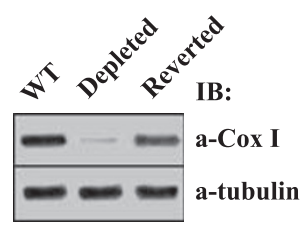

d

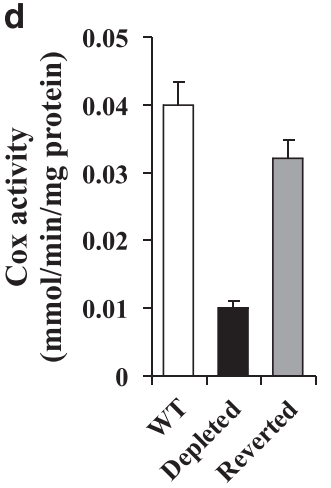

Figure 1 Depletion of mtDNA in PNT1A prostate epithelial cells. (a, $\mathbf{b})$ Total DNA was isolated from wild-type (WT), mtDNA-depleted (Depleted), and mtDNA-reverted (Reverted) PNT1A cells, and subjected to PCR (a) and Southern blotting (b) analysis. (a) On the left, $50 \mathrm{ng}$ total DNA/sample was subjected to PCR using primers for the mtDNA regions Cox I, D-loop and ND6. The nuclear DNA-encoded gene GAPDH was also amplified as control. The PCR products were visualized on $1.5 \%$ agarose gel stained with EtBr. $50 \%$-template controls $(25 \mathrm{ng})$ showed $\sim 50 \%$ decrease in yield for all primer combinations. M, molecular size marker. On the right, $15 \mathrm{ng}$ total DNA/sample was subjected to real-time PCR using primers for the mtDNA regions D-loop and Cox II, and a nuclear DNA marker ( $\beta$-actin). The amplification of mtDNA targets in mtDNAdepleted and -reverted PNT1A cells relative to wild-type PNT1A cells was calculated upon normalization to the reference $\beta$-actin as described in Materials and methods. Values are the mean \pm S.E. of three independent experiments. (b) Total DNA $(5 \mu \mathrm{g})$ was digested with Pvu II to linearizing the $16.6 \mathrm{~kb}$ human mtDNA and analyzed by Southern blot hybridization using an mtDNA-specific probe. DNA molecular size marker (M) is shown. (c) Levels of mtDNA-encoded Cox I protein in wild-type, mtDNAdepleted and mtDNA-reverted PNT1A cells were assessed by western blotting of total protein extracts using an anti-Cox I antibody. $\beta$-tubulin signals were used as loading controls. Three independent experiments were performed. (d) Cox activity in mitochondrial extracts from wild-type, mtDNA-depleted and mtDNA-reverted PNT1A cells was measured. Data represent mean \pm S.E. of duplicate measurements in three independent experiments 
with control cells $(P<0.001)$, as well as absence of smaller forms harboring large mtDNA deletions (Figure 1b). Furthermore, immunoblotting analysis for Cox I confirmed an $83 \% \pm 5$ decrease in mtDNA-depleted cells $(P<0.001$ Figure 1c), and levels returned to $74 \% \pm 7$ of normal after $\mathrm{EtBr}$ removal. Cox activity was also significantly decreased in mtDNA-depleted cells $(P<0.0001$; Figure $1 \mathrm{~d})$, consistent with acquisition of a respiratory-deficient phenotype.

MtDNA depletion promotes anoikis resistance and cell migration. We analyzed the ability of normal and mtDNA- depleted PNT1A cells to undergo detachment-induced apoptosis. To this effect, we measured cell viability after $48 \mathrm{~h}$ of growth in culture plates coated with poly-HEMA to prevent cell attachment. As shown in Figure 2A (panel a), although the viability of wild-type and reverted cells decreased by $\sim 20 \%(P<0.004)$, the effect upon mtDNA-depleted cells was negligible. To investigate whether the decreased viability resulted from increased apoptosis, we harvested the cells cultured onto poly-HEMA and evaluated the integrity of genomic DNA. As shown in Figure 2A (panel $b$ ), although wild-type and reverted cells exhibited DNA
A

a

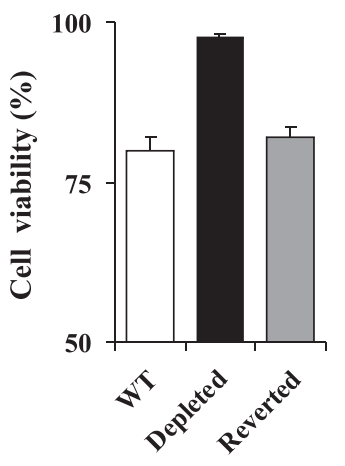

c PARP cleavage

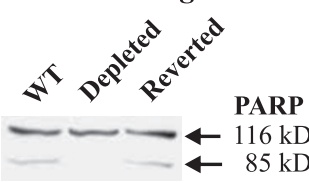

DNA fragmentation

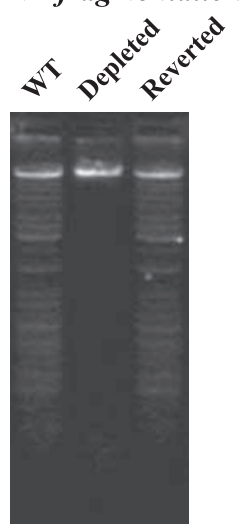

RP

$16 \mathrm{kD}$
B
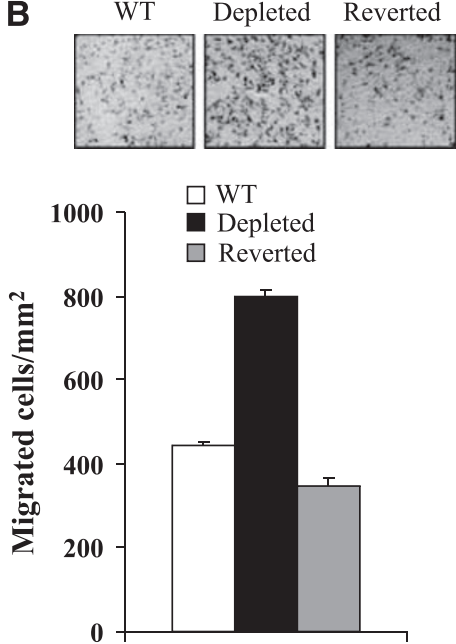

LN-1

C
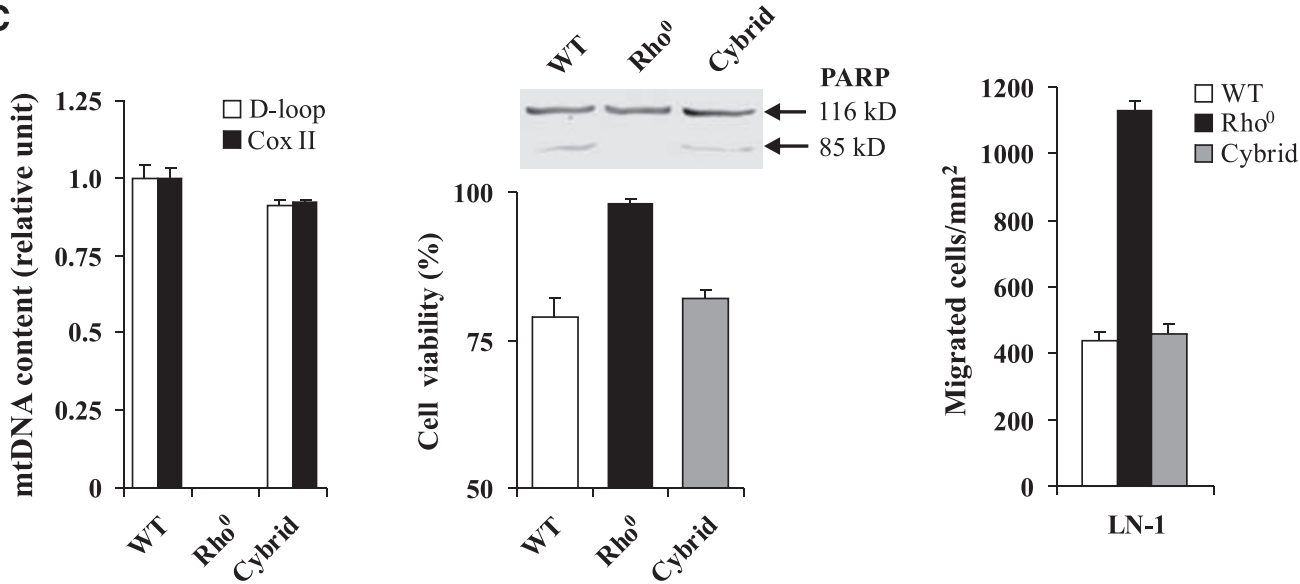

Figure 2 Depletion of mtDNA promotes resistance to anoikis and cell migration in PNT1A cells. (A) To assess sensitivity to anoikis, cells were cultured onto poly-HEMAcoated plates for $48 \mathrm{~h}$ after which cell viability (panel $a$ ), DNA fragmentation (panel $b$ ) and PARP cleavage (panel $c$ ) were measured by Trypan blue exclusion, agarose gel electrophoresis and western blotting, respectively. The antibody used to detect PARP cleavage recognized both the full 116-kDa form and the cleaved 85-kDa fragment. (B) Cell migration was assessed by plating $1.0 \times 10^{5}$ cells onto transwell insert filters coated with $\mathrm{LN}-1(10 \mu \mathrm{g} / \mathrm{ml})$. After $6 \mathrm{~h}$ at $37^{\circ} \mathrm{C}$, cells were fixed, stained with crystal violet, photographed and counted on the bottom of the filter. Measurements represent mean \pm S.E. of 10 random fields. A representative experiment of two is shown. (C) On the left, wild-type (WT), mtDNA-null (Rho ${ }^{\circ}$ ) and cybrid PNT1A cells derived from the fusion of PNT1A Rho ${ }^{\circ}$ with platelets, were assayed for mtDNA content by real-time PCR using two mtDNA markers (D-loop and Cox II) and a nuclear DNA marker ( $\beta$-actin). The relative amplification of mtDNA markers in Rho ${ }^{\circ}$ and cybrid PNT1A cells versus wild-type PNT1A cells was calculated upon normalization to the reference $\beta$-actin as described in Materials and methods. Values are the mean \pm S.E. of three independent experiments. In the middle and right panels, wild-type, Rho ${ }^{\circ}$ and cybrid PNT1A cells were assayed for resistance to anoikis and migration onto LN-1 as described in (A) and (B), respectively 
fragmentation, mtDNA-depleted cells showed no evidence of chromosomal DNA damage. We also investigated the cleavage of PARP, an early event in the apoptotic cascade that is widely regarded as a reliable marker of apoptosis onset, by western blotting analysis with an antibody that recognized both the $116-\mathrm{kDa}$ intact molecule and the 85/89kDa cleaved fragment. As shown in Figure 2A (panel $c$ ), the cleaved fragment was present in wild-type and reverted PNT1A but not in mtDNA-depleted cells. We then proceeded to explore whether the acquisition of anoikis resistance was accompanied by an increase in cell migration by measuring cell motility onto laminin-1 ( $\mathrm{LN}-1)$, an essential component of basement membranes. As shown in Figure 2B, mtDNA depletion enhanced cell motility onto $\mathrm{LN}-1$ by 2 -folds $(P<0.001)$, a behavior that was effectively inhibited by mtDNA replenishment. To demonstrate a causal relationship between depletion of mtDNA and the newly acquired cellular properties and rule out the possibility of a spurious behavior due to nuclear DNA damage, we repeated these experiments using PNT1A cytoplasmic hybrid cells (cybrids). To this effect, we first generated PNT1A $\mathrm{Rho}^{\circ}$ cells by further exposing mtDNA-depleted cells to $\mathrm{EtBr}$ until mtDNA was completely lost and subsequently introduced heterologous mtDNA by inducing cell membrane fusion with human platelets obtained from a healthy blood donor. As shown in Figure $2 \mathrm{C}, \mathrm{Rho}^{\circ}$ cells exhibited loss of sensitivity to anoikis and increased migration onto LN-1, and the phenotype was completely rescued in cybrids.

Depletion of mtDNA increases PI3K and pAkt2 levels. We next investigated which intracellular signaling pathway/s might be involved in mediating the effects of mtDNA depletion on prostate cell survival and migration. To this effect, we used a series of pharmacological inhibitors for different signaling pathways, including LY294002 (PI3K inhibitor), PD98059 (MEK inhibitor), SB302580 (p38 MAPK inhibitor) and SP600125 (JNK inhibitor). We found that only the PI3K inhibitor LY294002 was able to counter the effects of mtDNA depletion, albeit it was not completely specific as a lesser effect was also detectable in wild-type cells (Figure 3a). In similar experiments, LY294002 also inhibited anoikis resistance and migration in $\mathrm{LNCaP}$ and $\mathrm{PC}-3$ prostate carcinoma cells (data not shown). As mtDNA depletion has been reported to affect nuclear gene expression, ${ }^{17}$ we proceeded to investigate whether mtDNA depletion could promote $\mathrm{PI} 3 \mathrm{~K}$ signaling through regulation of p $85 \alpha$ regulatory and $\mathrm{p} 110(\alpha / \beta)$ catalytic subunit levels. As shown in Figure $3 \mathrm{~b}$, mtDNA depletion resulted in 2.6- and 1.6-fold increase in p85 and p110 levels, respectively $(P<0.001)$, which were similar to those detected in $\mathrm{LNCaP}$ and $\mathrm{PC}-3$ cells, and mtDNA replenishment restored $\mathrm{p} 85$ and p110 to wild-type levels. PI3K has several downstream effectors including several Akt family members and the mammalian target of rapamycin (mTOR). ${ }^{18}$ Thus, we explored these signaling pathways by using dominantnegative p85 (DNp85), Akt1, Akt2 and Akt3 siRNAs, as well as mTOR pharmacological inhibitor rapamycin. MtDNA depletion-induced resistance to anoikis and cell migration were significantly inhibited by DNp85 and Akt2 siRNAs, but not by Akt1 or Akt3 siRNAs or rapamycin (Figure 3c). The inhibitory effect of Akt2 was specific for mtDNA depletion, as Akt2 siRNAs had no detectable effect in wild-type PNT1A cells. Akt kinase activity correlates with phosphorylation on Thr-308 (pT308) and Ser-473 (pS473). Both phosphorylation events are essential to achieve maximal Akt activity. Using phospho-specific antibodies, we found that mtDNA depletion led to increased phosphorylation of Akt2 at both sites, and inhibition of $\mathrm{PI} 3 \mathrm{~K}$ reduced both phosphorylation events (Figure 3d).

Akt2 inhibition prevents prostate cancer cell survival and migration. To assess the relevance of the Akt2 pathway in prostate cancer, we examined Akt2 activity in LNCaP and PC-3 cancer cells. As shown in Figure $4 \mathrm{a}$, the levels of pT308 and pS473 Akt2 were similarly elevated in LNCaP, PC-3, and mtDNA-depleted PNT1A cells when compared with wild-type PNT1A cells. We also demonstrated that Akt2 siRNAs effectively prevented anoikis resistance and cell migration in carcinoma cells (Figure 4b).

Oxidative stress-induced mtDNA damage promotes Akt2 activation. MtDNA is very sensitive to the effects of oxidative agents. For instance, $\mathrm{H}_{2} \mathrm{O}_{2}$ treatment has been shown to promote extensive mtDNA damage through generation of apurinic sites, strand breaks and base modifications. ${ }^{19,20}$ To investigate whether mtDNA chemical damage would also activate Akt2 signaling thus mirroring the effects of mtDNA depletion, we treated wild-type PNT1A cells with either 2.5 or $5 \mu \mathrm{M} \mathrm{H}_{2} \mathrm{O}_{2}$ for up to $1 \mathrm{~h}$, after which $\mathrm{H}_{2} \mathrm{O}_{2}$ containing medium was replaced with fresh medium. Higher $\mathrm{H}_{2} \mathrm{O}_{2}$ concentrations proved to be cytotoxic (not shown). As shown in Figure $5 \mathrm{a}, \mathrm{H}_{2} \mathrm{O}_{2}$ elicited a time- and concentrationdependent increase in Akt2 phosphorylation, which returned to wild-type levels within 6 and $12 \mathrm{~h}$ of withdrawal at 2.5 and $5 \mu \mathrm{M} \mathrm{H}_{2} \mathrm{O}_{2}$, respectively. To confirm occurrence of mtDNA damage upon $\mathrm{H}_{2} \mathrm{O}_{2}$ exposure, we performed long PCR amplification of both full-length mtDNA and a 17.7-kb fragment from the nuclear $\beta$-globin gene cluster. This approach is based on the principle that oxidative DNA lesions will inhibit the progression of DNA polymerases along the template thus decreasing PCR product yield. ${ }^{19}$ As shown in Figure $5 \mathrm{~b}, \mathrm{H}_{2} \mathrm{O}_{2}$ treatment resulted in time- and concentration-dependent mtDNA damage whereas no discernible effect was observed upon nuclear DNA when compared with untreated controls (Figure $5 \mathrm{~b}$ and data not shown). The damage to the mtDNA was completely reversible after $12 \mathrm{~h}$ of incubation in fresh medium, with a higher repair rate among cells exposed to lower $\mathrm{H}_{2} \mathrm{O}_{2}$ concentration (Figure 5b).

Depletion of mtDNA regulates downstream substrates of PI3K/Akt2 involved in cell migration and survival. We further investigated potential downstream substrates of PI3K/ Akt2 that may be involved in mtDNA-dependent enhanced cell survival and migration. As shown in Figure 6a, mtDNA depletion-induced phosphorylation of GSK3 $\beta$ at Ser-9, a post-translational modification known to inactivate GSK3 $\beta$. Concomitantly, c-Myc and MMP-9 protein levels increased. In addition, mtDNA depletion induced phosphorylation and 

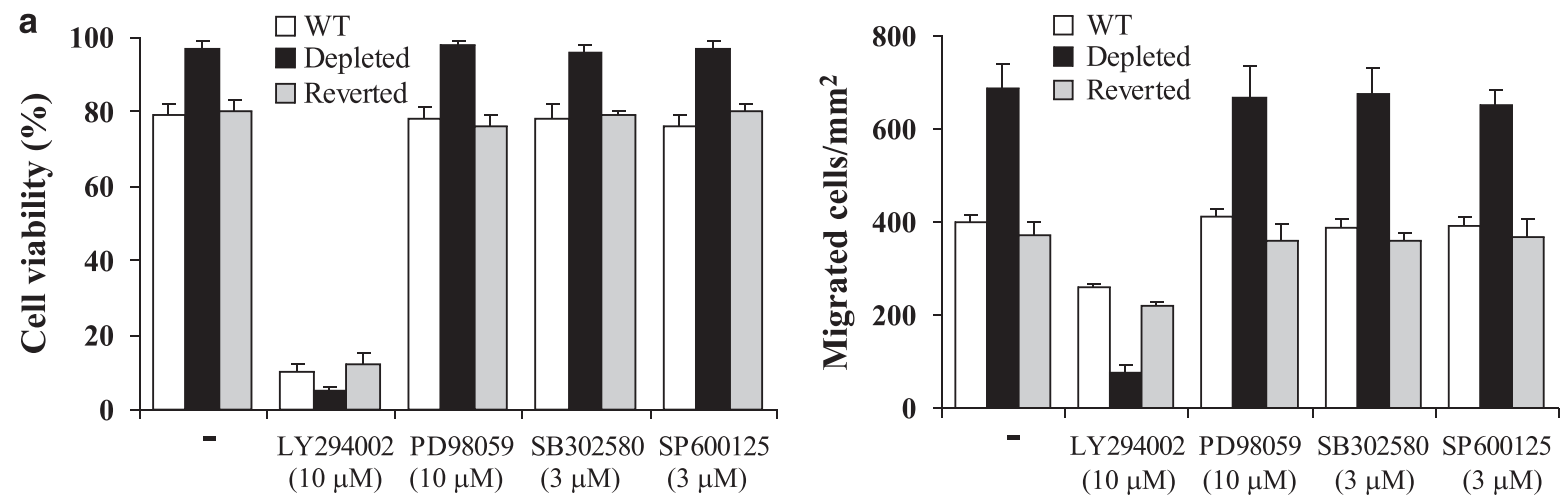

b

PNT1A
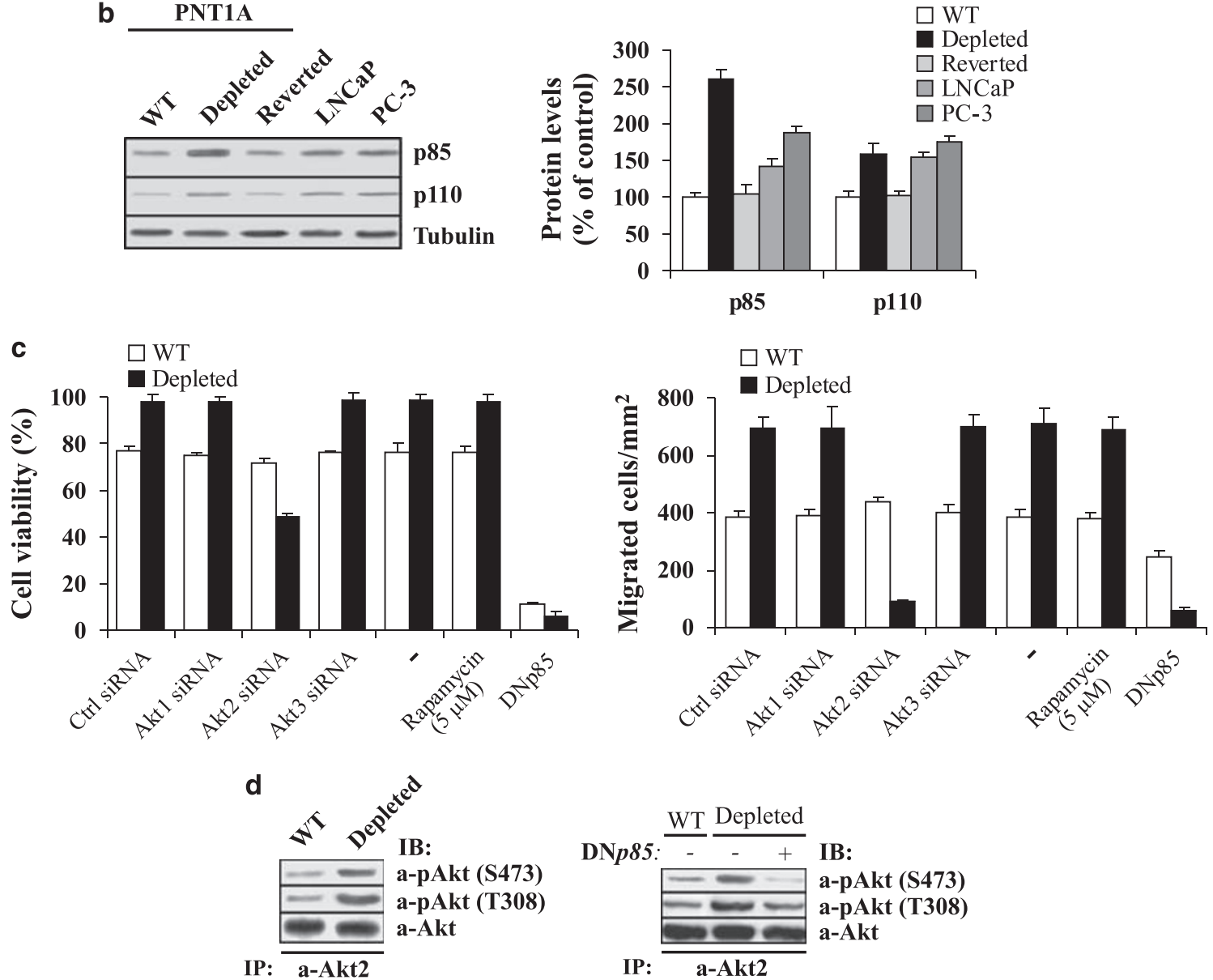

Figure 3 The effects of mtDNA depletion upon sensitivity to anoikis and cell migration are signaled through PI3K/Akt2. (a) Wild-type, mtDNA-depleted and -reverted PNT1A cells were treated with the pharmacological inhibitors LY294002 (PI3K inhibitor), PD98059 (MEK inhibitor), SB302580 (p38 MAPK inhibitor) or SP600125 (JNK inhibitor). On the left, cell viability was determined by Trypan blue exclusion $48 \mathrm{~h}$ after treatment under culture conditions on poly-HEMA-coated plates. On the right, migrated cells onto LN-1-coated transwells were counted $6 \mathrm{~h}$ after treatment. (b) Cell lysates were prepared from wild-type (WT), mtDNA-depleted and -reverted PNT1A cells, and from $\mathrm{LNCaP}$ and PC-3 carcinoma cells and immunoblotted with antibodies to $\mathrm{p} 85 \alpha$ or $\mathrm{p} 110 \alpha / \beta \mathrm{PI} 3$-kinase subunits. Levels of $\beta$-tubulin were used to assess loading conditions. The bar graph on the right was obtained by normalizing protein levels as a percentage of wild-type PNT1A cells. Mean \pm S.E. of three independent experiments is shown. (c) Wildtype (WT) and mtDNA-depleted cells were transiently transfected for $36 \mathrm{~h}$ with either Akt1, Akt2, Akt3 siRNAs or control siRNAs (Ctrl siRNA), or dominant-negative p85 (DNp85) or empty vector $(-)$, or were treated with the pharmacological inhibitor rapamycin, after which resistance to anoikis (left) and migration onto LN-1 (right) were measured. On the left, cell viability was determined by Trypan blue exclusion $48 \mathrm{~h}$ after plating on poly-HEMA-coated plates. On the right, migrated cells onto LN-1-coated transwells were counted $6 \mathrm{~h}$ after plating. Data in the graphs are presented as mean $\pm \mathrm{SE}$ of three independent experiments. (d) Wild-type and mtDNA-depleted PNT1A cells before (right) or after (left) $36 \mathrm{~h}$-transient transfection with a dominant-negative p85 form (DNp85) or empty vector $(-)$ were lysed, and total protein extracts were immunoprecipitated (IP) with anti-Akt2 antibody and analyzed by immunoblotting (IB) with anti-phospho-Ser-473 or -Thr-308 Akt and anti-Akt antibodies. Blots are representative of two independent experiments 
a

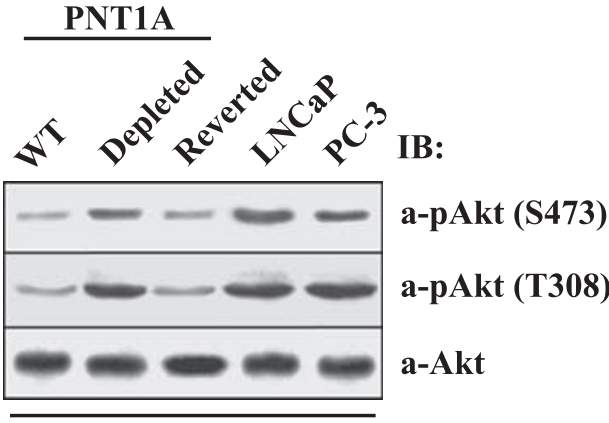

IP:

a-Akt2

b
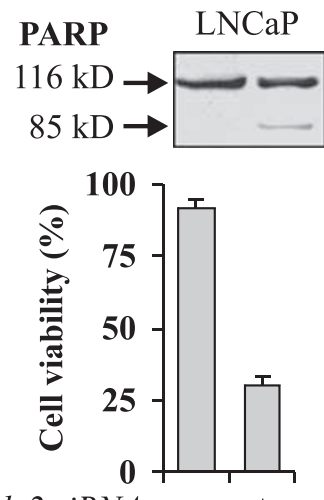

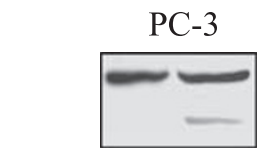

100

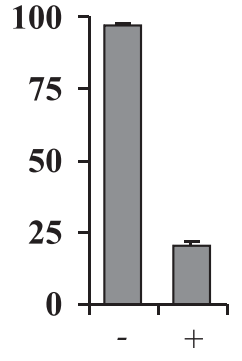

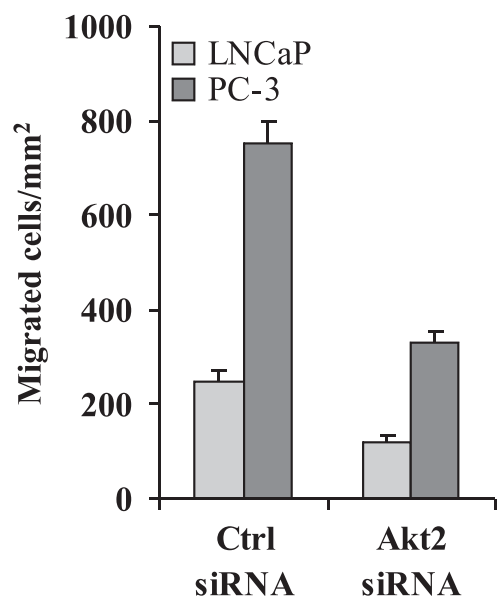

Figure 4 Akt2 inhibition prevents prostate cancer cell survival and migration. (a) Cell lysates from wild-type (WT), mtDNA-depleted and -reverted PNT1A cells, and from LNCaP and PC-3 prostate carcinoma cells were immunoprecipitated (IP) with anti-Akt2 antibody, and analyzed by immunoblotting (IB) with anti-phospho-Ser-473 or -Thr-308 Akt and anti-Akt antibodies. (b) LNCaP and PC-3 prostate cancer cells were transiently transfected with Akt2 siRNA or nonspecific siRNAs (Ctrl siRNA) and, $36 \mathrm{~h}$ after transfection, assayed for resistance to anoikis (left), and cell migration onto LN-1 (right). Sensitivity to anoikis was assessed by measuring cell viability by Trypan blue exclusion and PARP cleavage by immunoblotting in cells cultured onto poly-HEMA-coated plates for $48 \mathrm{~h}$. Migration was assessed by plating onto LN-1-coated transwell insert filters. After $6 \mathrm{~h}$, cells were fixed, stained with crystal violet, and cells migrated at the bottom of the filter were counted. Measurements represent mean \pm S.E. of 10 random fields. A representative experiment of two is shown

increased levels of Mdm2, another substrate of PI3K/Akt that downregulates p53, which was indeed decreased. Inhibition of Akt2 by siRNAs restored the expression profile of these substrates to a resting phenotype. LNCaP and PC-3 cells showed an expression pattern of PI3K/Akt substrates similar to mtDNA-depleted PNT1A cells (Figure 6a). We also found increased levels of glucose transporter 1 (GLUT1) in mtDNAdepleted PNT1A cells, as well as LNCaP and PC-3 cells (Figure 6a), which was associated with higher intracellular glucose content and increased lactate production, indicating a higher glycolytic activity compared with wild-type PNT1A cells (Figure 6b; $P<0.003$ ). Treatment with Akt2 siRNA was sufficient to restore GLUT1 levels as well as reduce glucose content and lactate production to wild-type levels (Figure 6a and c).

Expression of mtDNA-encoded protein Cox $I$ is decreased in prostate carcinoma cell lines and in a prostate carcinoma tissue microarray. To assess whether mtDNA mutation was a common phenomenon in prostate cancer, we evaluated the mtDNA content and Cox I protein expression in several prostate cancer cell lines. Androgen-dependent LNCaP and LAPC4 cells, and androgen-independent PC-3, DU145, and C4-2 prostate carcinoma cells exhibited mtDNA levels that were reduced by $53-85 \%(P<0.001)$ when compared with PNT1A cells (Figure 7A). Consistently, the expression of Cox I protein was reduced by $55-89 \%(P<0.001)$ (Figure 7B and data not shown). To further investigate whether these observations had any relevance in vivo, we analyzed Cox I protein expression in a prostate tissue microarray containing samples from benign and neoplastic prostate epithelium obtained from 80 patients with diagnosed prostate carcinoma (Figure 7C, panel d). Among the $13 \mathrm{mtDNA}$-encoded proteins we chose Cox I because measurement of Cox 1 expression by immunohistochemistry has been previously proven to be a useful marker of mtDNA deletion/ depletion $^{21,22}$ and validated antibodies are readily available. After elimination of cores with significant tissue loss after processing, 48 cores of normal prostate, 83 cores with $\mathrm{BPH}$, 31 cores with high-grade prostatic intraepithelial neoplasia (PIN), 91 cores with low-grade prostate carcinoma, and 62 cores with high-grade prostate carcinoma were examined. All normal prostate cores and 81 of 83 cores with BPH displayed strong granular staining for Cox I particularly in the basal cell layer (Figure 7C, panel a). Similarly, Cox I was highly expressed in $100 \%$ of PIN cores (not shown). On the other hand, $25 \%$ of prostate carcinoma cores exhibited virtual 

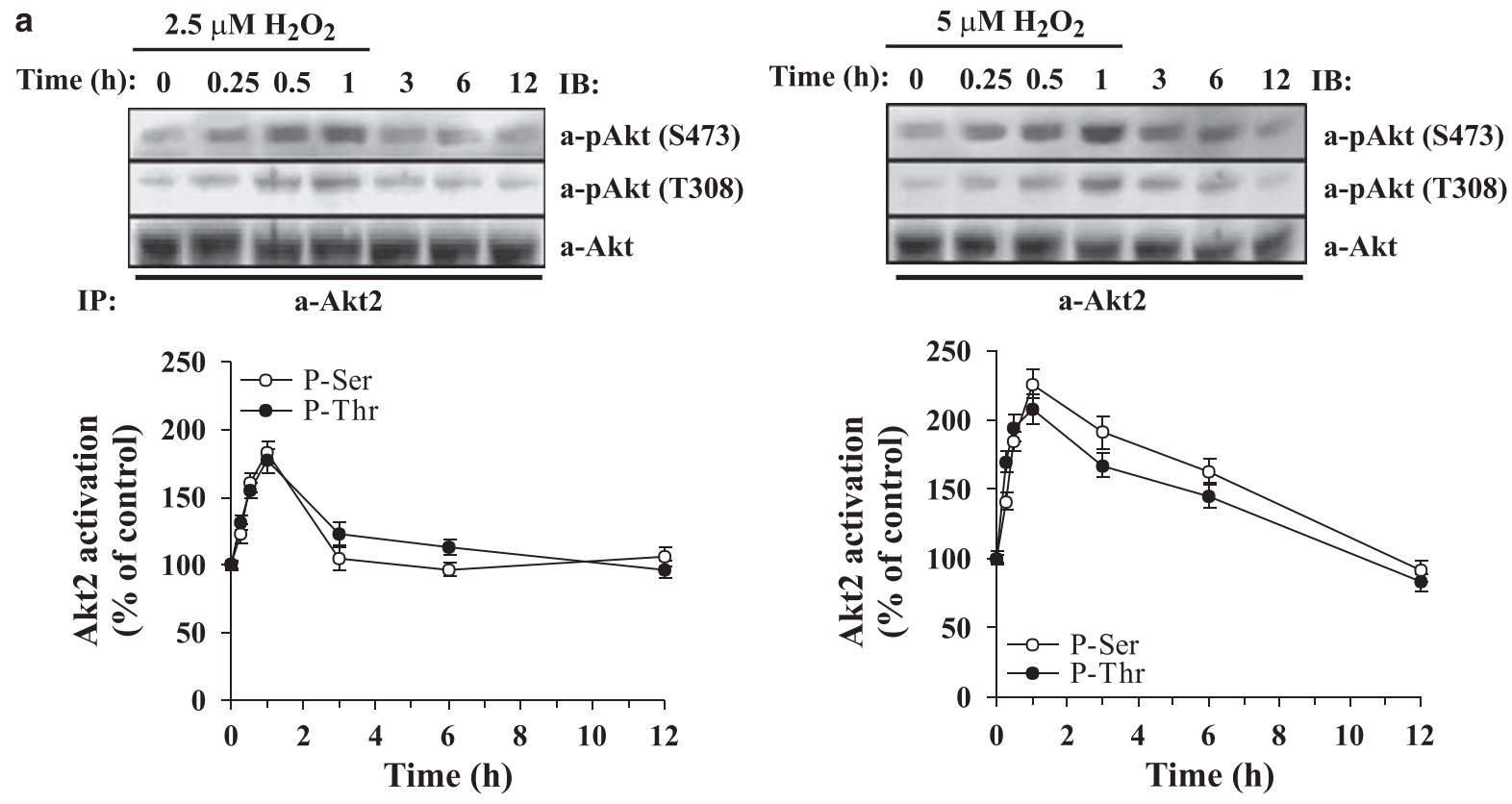

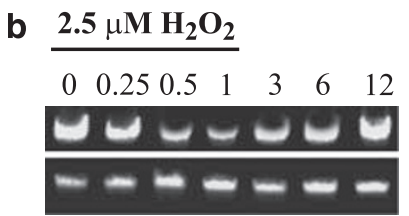

\author{
(h) \\ mtDNA (16.6 kb) \\ $\beta$-globin (17.7 kb)
}

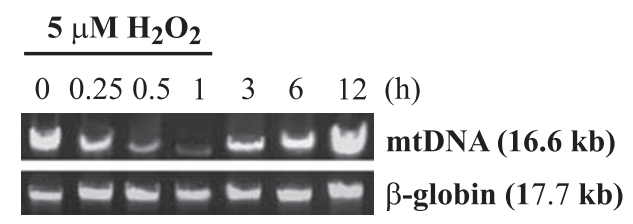

\begin{tabular}{cccc} 
& \multicolumn{3}{c}{ mtDNA lesions/10 kb } \\
\cline { 2 - 4 } Time (h) & $2.5 \mu \mathrm{M} \mathrm{H}_{2} \mathrm{O}_{2}$ & $5 \mu \mathrm{M} \mathrm{H}_{2} \mathrm{O}_{2}$ & Untreated \\
\cline { 2 - 4 } 0 & 0 & 0 & 0 \\
0.25 & $0.8 \pm 0.1$ & $1.2 \pm 0.1$ & 0 \\
0.5 & $1.2 \pm 0.3$ & $1.6 \pm 0.2$ & 0 \\
1 & $1.7 \pm 0.3$ & $2.3 \pm 0.3$ & 0 \\
3 & $0.9 \pm 0.1$ & $1.4 \pm 0.1$ & 0 \\
6 & $0.8 \pm 0.1$ & $1.3 \pm 0.2$ & 0 \\
12 & 0 & 0 & 0 \\
\hline
\end{tabular}

Figure 5 Oxidative stress-induced mtDNA damage promotes Akt2 activation in PNT1A cells. (a, b) PNT1A cells were treated with 2.5 or $5 \mu \mathrm{M} \mathrm{H}_{2} \mathrm{O}_{2}$ for $0-1 \mathrm{~h}$ and subsequently allowed to recover in fresh medium for the indicated times. Total proteins or DNA were extracted at different times and subjected to immunoprecipitation (a) or long PCR (b) analysis, respectively. (a) Cell lysates were immunoprecipitated (IP) with anti-Akt2 antibody, and analyzed by immunoblotting (IB) with anti-phospho-Ser-473 or -Thr-308 Akt and anti-Akt antibodies. The graph on the bottom was obtained by normalizing Akt2 phosphorylation levels as a percentage of untreated PNT1A cells. Mean \pm S.E. of three independent experiments is shown. (b) Full-length mtDNA (16.6 kb) and a $17.7 \mathrm{~kb} \beta$-globin fragment were amplified by long PCR. Gel photographs are representative of three independent experiments with similar results. The table on the bottom shows the conversion to lesion frequency of the decrease in mtDNA relative amplification. The data are expressed as the mean \pm S.E. of three independent experiments

absence of Cox I protein $(P<0.000001$ when compared with normal and hyperplastic prostate epithelium; Figure $7 \mathrm{C}$, panel $b$ ). Interestingly, 15 out of 114 Cox I-positive prostate carcinomas displayed a variable Cox I staining pattern among glands (Figure $7 \mathrm{C}$, panel $c$ ) with negative gland subsets exhibiting a higher histological grade (i.e., smaller and less organized) than adjacent positive ones.

\section{Discussion}

In vivo mtDNA is highly susceptible to genetic mutations partly due to lack of efficient DNA repair systems, absence of histones, and close vicinity to noxious ROS that originate from within mitochondria as by-products of respiration. ${ }^{23}$ In addition, mutations in mitochondrial deoxyguanosine kinase, thymidine kinase-2, and other nuclear genes encoding for proteins that are essential in mtDNA replication may contribute to overall genomic instability and eventual mtDNA depletion. ${ }^{24}$ In this study, we provide evidence demonstrating that mtDNA depletion alters fundamental biological processes involved in the pathophysiology of prostate carcinogenesis such as cell migration and apoptosis resistance through activation of the PI3K/Akt2 signaling pathway.

The ability of cells to escape apoptosis under anchorageindependent growth conditions is a crucial feature of carcinoma cells and thus considered as a bona fide evidence of neoplastic transformation. ${ }^{10}$ The newly acquired property is pivotal for the survival of single or small clumps of cells in the 
a
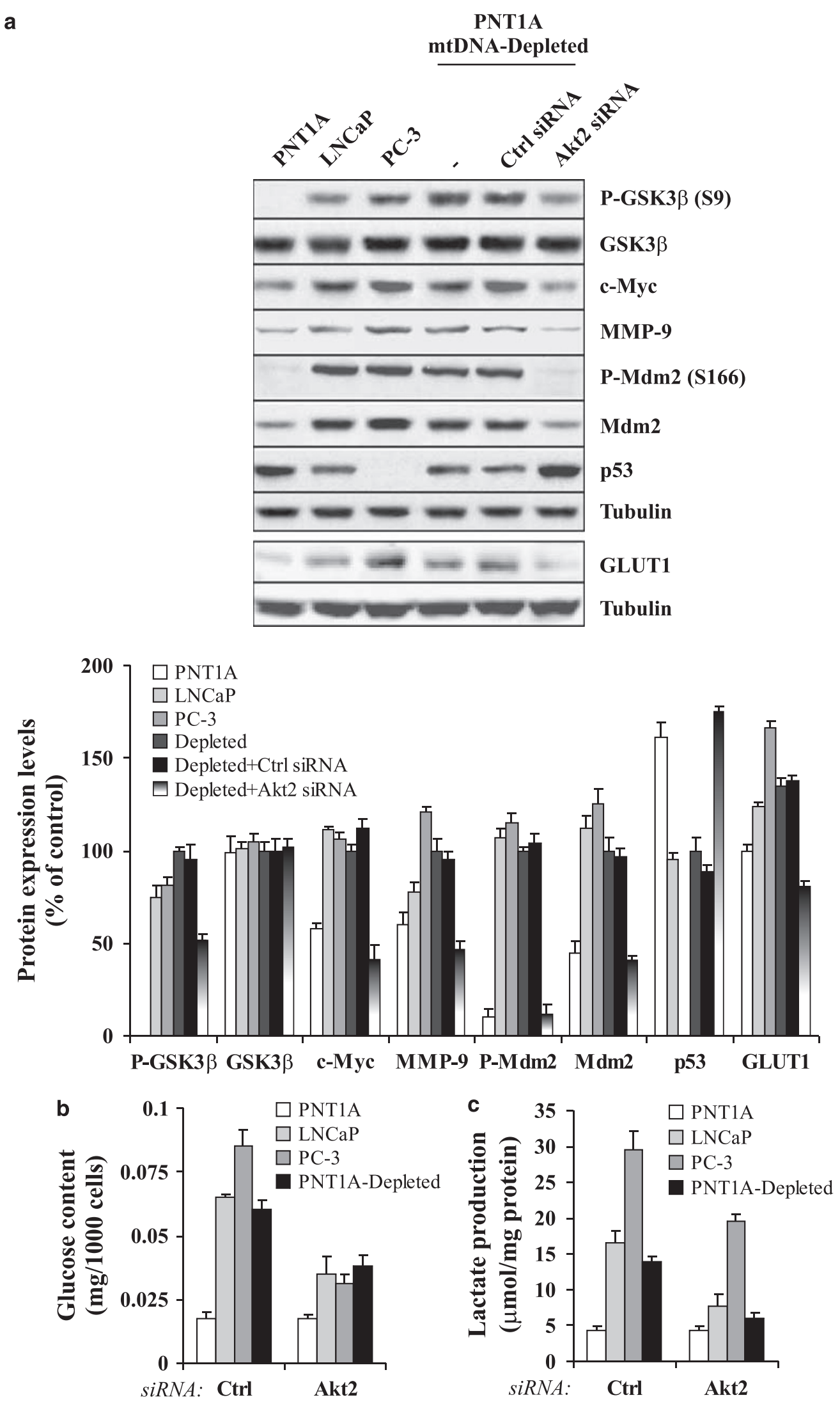
bloodstream during the metastatic process to distant organs. ${ }^{11}$ Neoplastic cells also exhibit increased motility onto basement membrane proteins that facilitates local invasion into the surrounding extracellular matrix. Our findings demonstrate that mtDNA depletion engenders resistance to detachment-induced apoptosis and increased cell migration

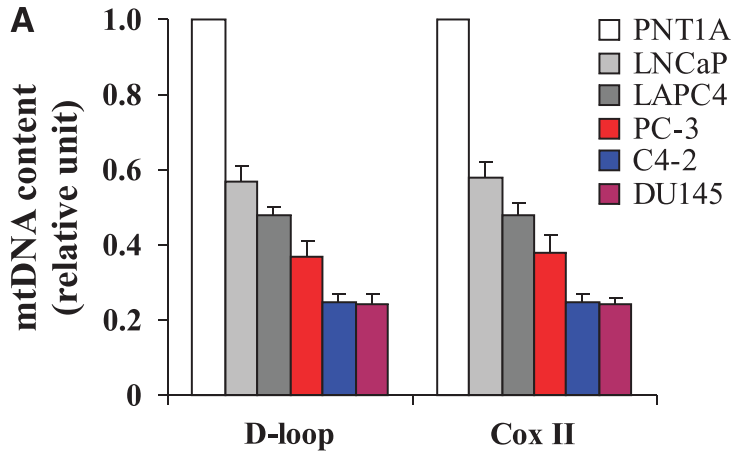

B

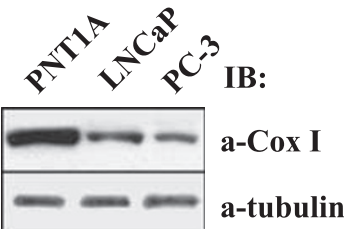
Benign prostate

b

Prostate carcinoma
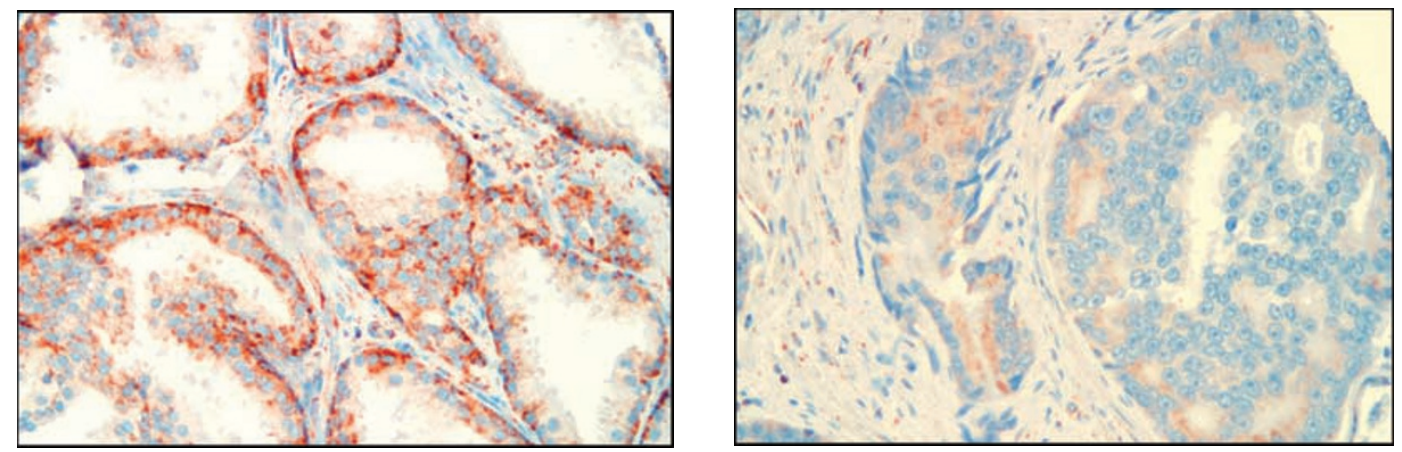

c Prostate carcinoma

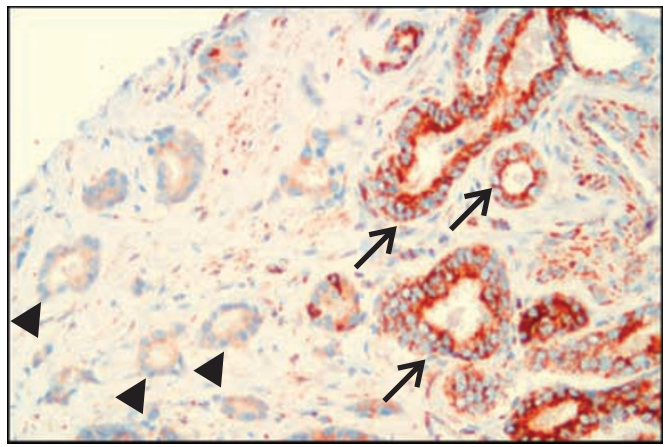

d Immunohistochemical analysis of Cox I expression
in prostate tissue microarrays

\begin{tabular}{cccc}
\hline & $\begin{array}{c}\text { Total cores } \\
\text { scored }\end{array}$ & $\begin{array}{c}\text { Positive } \\
\text { cores }\end{array}$ & $\begin{array}{c}\text { Negative } \\
\text { cores }(\%)\end{array}$ \\
\hline Normal $(N)$ & 48 & 48 & 0 \\
$B P H$ & 83 & 81 & 2.4 \\
Benign $(N+B P H)$ & 131 & 129 & 1.5 \\
$P I N$ & 31 & 31 & 0 \\
$L G C A$ & 91 & 68 & 25.3 \\
$H G C A$ & 62 & 46 & 25.8 \\
$P C(L G C A+H G C A)$ & 153 & 114 & 25.5 \\
\hline
\end{tabular}

Figure 7 Expression of $m t D N A$-encoded protein Cox I is decreased in prostate carcinoma cell lines and in a prostate carcinoma tissue microarray. (A) The mtDNA content was quantitated using real-time PCR. Two mtDNA markers (D-loop and Cox II) and a nuclear DNA marker ( $\beta$-actin) were used. The relative amplification of mtDNA markers in LNCaP, LAPC4, PC-3, DU145, and C4-2 versus PNT1A cells was calculated upon normalization to the reference $\beta$-actin as described in Materials and Methods. Values are the mean \pm S.E. of three independent experiments. (B) Levels of mtDNA-encoded Cox I protein in PNT1A, LNCaP, and PC-3 cells were assessed by western blotting of total protein extracts using an anti-Cox I antibody. $\beta$-tubulin signals were used as loading controls. (C) mtDNA mutations/depletion in prostate carcinoma in vivo was assessed by staining a prostate tissue microarray containing cores of normal prostate $(\mathrm{N})$, benign prostatic hyperplasia (BPH), high-grade prostatic intraepithelial neoplasia (PIN), low-grade adenocarcinoma (LGCA), and high-grade adenocarcinoma (HGCA) with a monoclonal antibody against Cox I. As shown in panel a, normal epithelial cells exhibited diffuse cytoplasmic staining that was more pronounced at the basal cell layer. A significant number of carcinoma cores exhibited virtual loss of Cox I, as depicted in panel $b$. A subset of cores exhibited a variable pattern of Cox I expression (panel c). Notably, the subpopulation of Cox I negative glands (arrowhead) exhibited histological features consistent with a higher Gleason grade than the positive subset $($ arrow) $(\times 200)$. A summary of Cox I protein expression in the five different stages of human prostate is shown in $d$

Figure 6 Depletion of mtDNA regulates downstream substrates of PI3K/Akt2. (a) Cell lysates were prepared from 70\% confluent wild-type and mtDNA-depleted PNT1A cells in the presence or absence of transiently transfected Akt2 siRNA or nonspecific siRNA (Ctrl siRNA), and from LNCaP and PC-3 cells, and immunoblotted with the indicated antibodies. The bar graph on the bottom was obtained by normalizing protein levels as a percentage of mtDNA-depleted PNT1A cells. Mean \pm S.E. of three independent experiments is shown. (b, c) Wild-type and mtDNA-depleted PNT1A cells, and LNCaP and PC-3 cells were transiently transfected with Akt2 siRNA or nonspecific siRNA (Ctr) and, after $48 \mathrm{~h}$, intracellular glucose content (b) and extracellular lactate production (c) were measured. Data represent mean \pm S.E. of duplicate measurements in two independent experiments 
onto basement membrane proteins, suggesting that mtDNA mutations may contribute to the establishment of phenotypic changes commonly seen in neoplastic cells. Nevertheless, this abnormal cell behavior may be completely rescued by restoring mtDNA.

By using several pharmacological inhibitors to disrupt various cellular pathways, we demonstrate that PI3K/Akt2 signaling is involved in mtDNA depletion-induced resistance to anoikis, as well as increased cell migration. A link between mtDNA depletion and Akt activation has been previously reported in HL-60 (leukemia) and Raji (lymphoma) cells, ${ }^{25}$ suggesting that upregulation of Akt may represent a common denominator in the acquisition of neoplastic features related to mtDNA depletion in hematologic and solid organ neoplasms. Furthermore, we demonstrate that transient oxidative mtDNA damage may also activate Akt in prostate cells as previously shown in other cell types, ${ }^{26-28}$ further supporting a role for mtDNA in modulating the Akt signaling pathway. Although $\mathrm{PI}$ KK/Akt activation has been previously implicated in promoting prostate cancer cell invasion, ${ }^{29,30}$ the identification of Akt2 is novel. Three isoforms of Akt (Akt1, Akt2, and Akt3) exist in mammalian cells. Whereas they are known to share common substrates, their specific function is still an intriguing and challenging subject. Recent studies have shown that different Akt isoforms may play opposite roles in regulating cell functions; for example, Akt1 activation inhibits cell migration whereas Akt2 may promote it. ${ }^{31,32}$ Consistently, we found that the mtDNA-dependent increase in migration and anoikis resistance was mediated by Akt2 but not Akt1 or Akt3. Furthermore, we have noted that Akt1 protein levels are reduced after mtDNA depletion (L Moro, unpublished results). This may be the first instance where mtDNA is shown to be involved in the activation of specific Akt isoforms. It is worth mentioning that although PI3K inhibition has a noticeable effect upon wild-type and mtDNA-depleted PNT1A cells, selective Akt2 inhibition by siRNA affects only mtDNAdepleted PNT1A and prostate carcinoma cells but has no effect on wild-type PNT1A cells. Hence, Akt2 appears to be a more suitable target for therapeutic manipulation rather than $\mathrm{PI} 3 \mathrm{~K}$, which is involved in other crucial processes in normal cells. The downstream Akt2 signaling results in downregulation of GSK3 $\beta$, which is conceivably involved in cell migration in various ways. In the one hand, GSK3 $\beta$ inactivation results in accumulation of its downstream target c-myc, a known regulator of cell migration. ${ }^{33}$ In addition, GSK3 $\beta$ phosphoinactivation also promotes expression of the gelatinase MMP$9,{ }^{34}$ and we have recently demonstrated the role of MMP-9 in promoting prostate cancer cell migration and invasion. ${ }^{30}$ Akt2 also supports survival by phosphorylating the ubiquitin ligase protein Mdm2, which in turn promotes ubiquitination and degradation of p53 protein. $^{35}$ Hence, by promoting p53 degradation, Akt activation has a negative effect upon the ability of cells to undergo apoptosis in response to abnormal stress thus enhancing tumorigenesis. ${ }^{35}$

Previous studies have demonstrated an important role of activated Akt in upregulating glycolysis through different mechanisms, including increased expression of glucose transporters. ${ }^{18}$ Avadhani and co-workers reported that mtDNA depletion in A549 lung cancer cells promotes overexpression of hexokinase, the enzyme catalyzing the first reaction in glycolysis. ${ }^{7}$ Here, we demonstrate that mtDNA depletion increases GLUT1 levels through Akt2 activation, which conceivably mediates an increased glucose uptake and lactate production. Hence, mtDNA mutations may promote a highly glycolytic phenotype that is characteristic of tumor cells partly through Akt2 activation. Moreover, the Akt-driven glycolytic phenotype may support cell survival by preventing Bax activation. ${ }^{36}$

We also show that inappropriate PI3K activation in mtDNAdepleted cells results from upregulation of the p85 and p110 subunits. The significance of these changes in the pathobiology of prostate cancer is supported by the findings of increased p85 and p110 levels in prostate cancer cell lines (Figure 3) and in human prostate adenocarcinomas in vivo. ${ }^{29}$ Loss of PTEN, a negative regulator of the PI3K activity, has also been implicated in PI3K/Akt constitutive activation in prostate carcinoma. ${ }^{37}$ Hence, it is plausible that mtDNA depletion or mutations represent a PTEN-independent genetic event that contributes to PI3K/Akt activation in cancer cells. Avadhani and co-workers have previously shown that mtDNA depletion may induce the expression of pro-invasive and anti-apoptotic factors during cancer progression through a mechanism that ultimately results in elevated cytoplasmic $\left[\mathrm{Ca}^{2+}\right]^{6,7}$ Whether mtDNA depletion promotes upregulation of $\mathrm{PI3K}$ through $\mathrm{Ca}^{2+}$-mediated signaling or may involve $\mathrm{Ca}^{2+}$-independent mechanism/s remains an important question yet to be answered.

We also provide evidence demonstrating that mtDNA defects occur in vivo by analyzing the expression of the mtDNA-encoded Cox I protein in human prostate cancer cell lines and prostatectomy specimens. When comparing mtDNA content and Cox I levels in minimally invasive androgendependent prostate cancer cells with highly tumorigenic/ highly metastatic androgen-independent cells we found an inverse relationship between Cox I protein and tumorigenicity, albeit all cell lines exhibited decreased mtDNA and Cox I levels when compared with PNT1A cells. Similar results were obtained by immunohistochemical analysis of Cox I expression in prostate carcinoma samples in a tissue microarray in which the normal controls consisted of matched normal epithelial glands found elsewhere in the prostatectomy specimens. Our results agree with previous reports showing decreased expression of the mtDNA-encoded proteins Cox I and Cox II in prostate carcinomas. ${ }^{2,38}$ More recently, Abril J et al. $^{39}$ reported a reduction in ATPase 6 and Cox II mRNA levels in prostate tumor samples when compared with paired normal counterparts. Petros et al. ${ }^{2}$ has also shown that introduction of a mutant ATPase 6 gene in PC-3 cells further increases their tumorigenicity in nude mice. Taken together, these results confirm that decreased expression of mtDNAencoded proteins involved in electron transfer (Cox I and II) and ATP synthesis (ATPase6) is a frequent event in prostate carcinoma. Here, we provide evidence that those events may contribute to acquisition of anoikis resistance, a feature of cancer cells. Evidence linking changes in mtDNA content to more advanced neoplastic phenotype had been suggested in recent studies demonstrating that $\mathrm{LNCaP}$ cells readily become androgen-independent and highly malignant after mtDNA depletion. ${ }^{8,9}$ Although an inverse relationship between Cox I expression and Gleason grade was not observed 
in our study, we noticed that groups of glands exhibiting histological features associated with higher Gleason grade (small size and angulated contours) displayed substantially reduced Cox I levels when compared with lower grade carcinoma glands within the same specimen. The presence of Cox I-positive and -negative cancerous glands in the same prostate cancer specimen is intriguing and would support the hypothesis that somatic mtDNA mutations may arise or disappear at different junctures throughout the neoplastic transformation. ${ }^{23}$

Overall, our study demonstrates that mtDNA depletion enables survival under anchorage-independent conditions and increases cell migration by upregulating PI3K/Akt2 and downstream signaling molecules GSK3 $\beta /$ Myc, GSK3 $\beta /$ MMP-9, Mdm2/p53, and GLUT1. A better understanding of the mitochondrial network of communication with other cell organelles will certainly facilitate the development of new therapeutic strategies aimed at limiting the effect of oncogenic signals resulting from mtDNA mutations, a common event in multiple neoplasms, including prostate carcinoma.

\section{Materials and Methods}

Cell culture and reagents. PNT1A cells were grown in RPMI- 1640 supplemented with $10 \%$ heat-inactivated fetal bovine serum (FBS). Reversible mtDNA depletion through cellular exposure to low concentration of $\mathrm{EtBr}$ is a powerful strategy that has been widely used in the characterization of cellular processes that may be influenced by alterations in the mtDNA. ${ }^{17,40}$ To induce mtDNA depletion, PNT1A cells were treated with $\mathrm{EtBr}(100 \mathrm{ng} / \mathrm{ml})$. After 30 days of growth in the presence of EtBr, cells were screened for mtDNA content by PCR and southern hybridization, added with $1 \mathrm{mM}$ pyruvate and $50 \mu \mathrm{g} / \mathrm{ml}$ uridine, and frozen as aliquots in liquid nitrogen. Reverted cells were obtained by growing mtDNAdepleted cells for 15 days in the absence of EtBr. To ensure steady mtDNA levels, aliquots of the same cell isolate were used in all experiments. To generate mtDNAless PNT1A cells $\left(R h 0^{\circ}\right), m$ tDNA-depleted cells were grown for additional 15 days in the presence of EtBr. Rho $0^{0}$ PNT1A cells were then kept in culture in the presence of pyruvate and uridine, but in the absence of EtBr. PC-3 and LNCaP cells were kept in culture as described earlier. ${ }^{14}$ DU145, C4-2 and LAPC4 prostate carcinoma cell lines were a kind gift of Dr JT Hsieh (UT Southwestern Medical Center, Dallas, TX, USA). DU145 were kept in culture in RPMI-1640 supplemented with 10\% FBS, $2 \mathrm{mM}$ glutamine, and $1 \mathrm{mM}$ pyruvate. C4-2 cells were grown in T-medium supplemented with $5 \%$ FBS. LAPC4 cells were grown in $1 \mathrm{X}$ Iscoves with $10 \%$ FBS and $4 \mathrm{mM}$ glutamine. LY294002, PD98059, SB302580, SP600125, and rapamycin were purchased from Calbiochem (San Diego, CA, USA).

PCR analysis. Total DNA containing nuclear and mitochondrial DNA was isolated from $1 \times 10^{6}$ cells using the NucleoSpin kit (Macherey-Nagel Gmb, Germany), according to the manufacturer's instructions. Different regions of the mitochondrial genome were amplified under standard PCR conditions using mtDNA-specific primers. Amplifications were performed in $50 \mu \mathrm{l}$ reactions comprising of 25 or $50 \mathrm{ng}$ DNA, $0.1 \mathrm{mM}$ dNTPs (Roche, Indianapolis, IN, USA), $1 \times$ PCR buffer, $1.5 \mathrm{mM} \mathrm{MgCl}_{2}, 0.5 \mu \mathrm{M}$ each primer (Operon Biotechnologies $\mathrm{GmbH}$, Cologne, Germany), $2.5 \mathrm{U}$ Taq polymerase (Roche), and nuclease-free $\mathrm{H}_{2} \mathrm{O}$ (Roche). Primer sequences were as follows: $5^{\prime}$-TGGAGCCTCCGTAGACCTAA-3' sense and $5^{\prime}$-TCCGAAGCCTGGTAGGATAA-3' antisense for cytochrome oxidase I (no. 6321-6660; Cox I), 5'-CACCCTATTAACCACTCACG-3' sense and 5'TGAGATTAGTAGTATGGGAG-3' antisense for D-loop (no. 15-484), 5'. ATCCTACCTCCATCGCTAAC- $3^{\prime}$ sense and 5'-AGCCTTCTCCTATTTATGGG- $3^{\prime}$ antisense for NADH dehydrogenase subunit 6 (no. 14371-14610; ND6). Primers for the nuclear DNA-encoded glyceraldehyde 3-phosphate dehydrogenase (GAPDH) have been described earlier. ${ }^{15}$ PCRs were amplified in a Perkin Elmer CETUS PCR System (Perkin Elmer Life Sciences) using the following cycling protocol, where $X$ represents the annealing temperature: $94^{\circ} \mathrm{C}$ for $3 \mathrm{~min}, X^{\circ} \mathrm{C}$ for $3 \mathrm{~min}, 72^{\circ} \mathrm{C}$ for $1 \mathrm{~min}$ (first cycle) and $94^{\circ} \mathrm{C}$ for $1 \mathrm{~min}, X^{\circ} \mathrm{C}$ for $1 \mathrm{~min}, 72^{\circ} \mathrm{C}$ for $1 \mathrm{~min}$ for $35 \mathrm{cycles}$. The final cycle was modified to allow for a $10 \mathrm{~min}$ extension at $72^{\circ} \mathrm{C}$. Annealing temperatures used were as follows: $46^{\circ} \mathrm{C}$ for D-loop, $55^{\circ} \mathrm{C}$ for Cox I, ND6 and GAPDH. The PCR products were electrophoresed on a 1.5\% agarose gel stained with $\mathrm{EtBr}$ and photographed under UV light.

Real-time PCR. Real-time PCR was carried out in an Applied Biosystems Inc. (ABI) Prism 7000 Sequence Detection using the SYBR-Green PCR Master Mix (Qiagen, Valencia, CA, USA). Primers for two mtDNA markers (D-loop and Cox II) and a nuclear DNA marker ( $\beta$-actin) were used. ${ }^{9}$ Amplifications were performed in $25 \mu \mathrm{l}$ reactions comprising of $15 \mathrm{ng}$ total DNA, 1 X SYBR-Green PCR Master Mix (Qiagen) with $3.5 \mathrm{mM} \mathrm{MgCl}_{2}$, and $0.3 \mu \mathrm{M}$ each primer (Operon Biotechnologies $\mathrm{GmbH}$ ). Triplicate reactions were performed for each marker in a 96-well plate using a two-step amplification program of initial denaturation at $95^{\circ} \mathrm{C}$ for $15 \mathrm{~min}$, followed by 35 cycles of $94^{\circ} \mathrm{C}$ for $20 \mathrm{~s}$ and $61^{\circ} \mathrm{C}$ for $30 \mathrm{~s}$. Standard curves were generated from each experimental plate using serial 5 -fold dilutions of genomic DNA. The authenticity of the PCR products was verified by agarose gel electrophoresis. The comparative cycle threshold $\left(C_{t}\right)$ method was used to analyze the data by generating relative values of the amount of mtDNA. Relative quantitation $\left(R_{\mathrm{c}}\right)$ of mtDNA was calculated after determination of the difference between $C_{t}$ of the given mtDNA marker $A$ and that of the calibrator nuclear marker $B(\beta$-actin) in EtBr-treated PNT1A cells, cybrids, or prostate carcinoma cell lines $\left(\Delta C_{\mathrm{t} 1}=C_{\mathrm{t} 1 \mathrm{~A}}-C_{\mathrm{tB}}\right)$ and wildtype PNT1A cells $\left(\Delta C_{\mathrm{t} 0}=C_{\mathrm{t} 0 \mathrm{~A}}-C_{\mathrm{tB}}\right)$, using the $R_{\mathrm{C}}=2^{-\Delta \Delta C_{\mathrm{t}(1-0)}}$ formula. Experiments were repeated two times.

Southern blotting. To analyze mtDNA content and integrity, total DNA was isolated from cells $\left(1-5 \times 10^{6}\right)$ using the Nucleospin kit (Macherey-Nagel) according to the manufacturer's instructions. Total cellular DNA $(5 \mu \mathrm{g})$ was digested with Pvu II to linearizing the $16.6 \mathrm{~kb}$ human mtDNA and analyzed by Southern blot hybridization using the mtDNA-specific $5^{\prime}$-end labeled synthetic DNA sequence 5'-AACACTATACCTATTATTCGGCGCATGAGCTGGAGTCCTAGGCACAGCTC-3'. MtDNA signals were quantitated in a Bio-Rad GS-700 imager.

Detection of DNA damage by long PCR. Detection of DNA damage by long PCR is based on the notion that any oxidative DNA lesions (base modifications, apurinic sites, strand breaks) will cause a block in the progression of DNA polymerases (e.g., Taq and $r$ Tth polymerase). High molecular weight DNA was isolated using the DNeasy Blood and Tissue kit (Qiagen) as described by the manufacturer. The entire mtDNA genome $(16.6 \mathrm{~kb})$ was amplified using a single back to back primer set (mt1076F: GTGTTATCCCAGTTTGGGTCTTAGCTA, mt1135R: CCAGAACACTACGAGCCACAG). Primers for the $17.7 \mathrm{~kb} 5^{\prime}$-flanking region of the $\beta$-globin gene were as described by Yakes et al. ${ }^{19}$ Here, $40 \mathrm{ng}$ of template DNA, 1.25 units LA Advantage ${ }^{\circledR}$ Genomic LA Polymerase (Clontech), $2.5 \mu \mathrm{L}$ LA buffer, $0.4 \mathrm{mM}$ each of dNTPs, and $0.2 \mu \mathrm{M}$ of primers were mixed with $\mathrm{dH}_{2} \mathrm{O}$ to a final volume of $25 \mu \mathrm{l}$. Cycling parameters were as follows: $94^{\circ} \mathrm{C}$ for $1 \mathrm{~min}$, followed by 35 cycles of $94^{\circ} \mathrm{C}$ for $21 \mathrm{~s}, 68^{\circ} \mathrm{C}$ for $15 \mathrm{~min}$, a final elongation step of $72^{\circ} \mathrm{C}$ for $10 \mathrm{~min}$ and hold at $4^{\circ} \mathrm{C}$. PCR products were visualized on $0.9 \%$ agarose gel. The frequency of DNA lesions was calculated by normalizing the amplification of damaged (treated) samples to the amplification of non-damaged controls as described by Yakes et al..$^{19}$ To ensure that differences in long PCR amplifications were not because of template copy number differences or DNA quality problems unrelated to chemically induced damage, DNA sample quality was tested by realtime PCR as described above using an 80-bp fragment in the mtDNA (Cox $I^{9}$ ) and a 101-bp fragment in the $\beta$-globin gene $(\beta$-globin primers were: BglobinF, GTGCACCTGACTCCTGAGGAGA; BglobinR, CCTTGATACCAACCTGCCCAG). Small DNA target regions $(<150 \mathrm{bp})$ are indeed unlikely to suffer any insult, and thus may serve as indicators of relative copy number and PCR quality of the DNA extracts.

Western blotting. Total protein extracts were analyzed by immunoblotting as described previously. ${ }^{15,16}$ Monoclonal antibody to Cox I was purchased from Molecular Probes (Carlsbad, CA, USA). Antibodies to phospho-Akt Ser 473, murine double minute 2 (Mdm2), matrix metalloproteinase-9 (MMP-9) and $\beta$-tubulin have been described earlier. ${ }^{15,16,30}$ Polyclonal antibody to $p 85 \alpha$ and monoclonal antibody to $c-M y c$ (9E10) were from Sigma. Monoclonal antibody to p53 (Ab-6) was purchased from Calbiochem (San Diego, CA, USA). Anti-p110 $\alpha / \beta$, anti-phosphoAkt T308, anti-Akt, anti-GLUT1 and monoclonal antibodies to GSK3 $\beta$ (1F7), phospho-S9-GSK3 $\beta$ (2D3), Akt1 (B-1), Akt2 (F-7) and Akt3 (4H23) were purchased from Santa Cruz Biotechnologies. The antibody for phospho-Mdm2 was purchased from Cell Signaling Technology Inc. (Danvers, MA, USA). To analyze poly(adenosine diphosphate [ADP]-ribose) polymerase (PARP) cleavage, cells were washed two times in cold PBS and lysed in $50 \mathrm{mM}$ Tris- $\mathrm{HCl}(\mathrm{pH} 7.5), 150 \mathrm{mM}$ 
$\mathrm{NaCl}, 2 \mathrm{mM}$ EDTA, $50 \mathrm{mM}$ NaF, $1 \%$ Triton X-100, $1 \%$ Na deoxycholate, $0.1 \%$ SDS, $1 \mathrm{mM}$ dithiothreitol, $5 \mathrm{mM}$ Na orthovanadate, $1 \mathrm{mM}$ phenylmethylsulphonyl fluoride, $38 \mu \mathrm{g} / \mathrm{ml}$ aprotinin, frozen at $-80^{\circ} \mathrm{C}$ for $12 \mathrm{~h}$, then sonicated for $10 \mathrm{~s}$, and centrifuged at $14000 \times \mathrm{g}$ for $20 \mathrm{~min}$ at $4^{\circ} \mathrm{C}$. Protein extracts $(100 \mu \mathrm{g})$ were electrophoresed on $10 \%$ SDS-polyacrylamide gel under reducing conditions and transferred to polyvinylidene diflouride (PVDF) membranes (Millipore, Bedford, MA, USA). Immunoblotting was performed using a 1:500 dilution of monoclonal antibody to PARP (Ab-2, Calbiochem).

To perform a coupled immunoprecipitation-immunoblotting assay, the whole cell extract ( $0.5 \mathrm{mg}$ of protein) was first precleared and then incubated overnight at $4{ }^{\circ} \mathrm{C}$ with $2 \mu \mathrm{g}$ monoclonal antibody to Akt2. Immunocomplexes were recovered by binding to protein G-Sepharose (Sigma) and analyzed by 7.5\% SDS-PAGE under reducing conditions followed by transfer to PVDF membrane. Filters were immunoblotted using polyclonal antibodies to phospho-Akt Ser-473 or Thr-308, or Akt.

Anoikis assay. Cells $\left(5 \times 10^{5}\right.$ cells per $2 \mathrm{ml}$ per well) were plated onto polyHEMA-coated 6-well plates to prohibit attachment. After 48 -h incubation at $37^{\circ} \mathrm{C}$, viability of the cells was measured using Trypan blue exclusion. Apoptosis was measured by analyzing PARP cleavage in an immunoblotting analysis as described above, and by DNA fragmentation analysis. Briefly, cells were lysed in $10 \mathrm{mM}$ EDTA, $0.2 \%$ Triton X-100, $10 \mathrm{mM}$ Tris- $\mathrm{HCl}(\mathrm{pH} 7.5)$. Lysates were digested with proteinase $\mathrm{K}(0.5 \mathrm{mg} / \mathrm{ml})$, extracted two times with phenol/chloroform and nucleic acids were recovered by ethanol precipitation. Pellets were resuspended in $10 \mathrm{mM}$ Tris-HCl, $1 \mathrm{mM}$ EDTA ( $\mathrm{pH} 7.5$ ), digested with RNase A ( $50 \mathrm{ng} / \mathrm{ml}$; Promega) and subjected to electrophoresis on a $1.5 \%$ agarose gel containing $0.1 \mu \mathrm{g} / \mathrm{ml} \mathrm{EtBr}$. Gels were photographed under UV light.

Cell migration assay. Cells $\left(1 \times 10^{5}\right)$ were seeded on $8-\mu \mathrm{m}(12-\mu \mathrm{m}$ for $\mathrm{LNCaP}$ ) pore-sized transwell Boyden chamber (Corning Costar) coated overnight at $4^{\circ} \mathrm{C}$ with $10 \mu \mathrm{g} / \mathrm{ml}$ laminin-1 (LN-1). After $6 \mathrm{~h}$ at $37^{\circ} \mathrm{C}$, migrated cells were fixed with $3 \%$ paraformaldehyde, stained with crystal violet, and the number of cells per square millimeter on the bottom was counted (average and S.E. of 10 random fields). Each experiment was performed in duplicate.

Generation of cybrids by platelet transformation of mtDNA-less PNT1A cells. Rho ${ }^{\circ}$ PNT1A cells were transformed with platelets obtained from a 38-year-old healthy blood donor (Di Venere Hospital, Unit of Transfusion Medicine; Bari), essentially as described by Higuchi et al. ${ }^{8}$ Briefly, platelets were isolated from 10-ml samples of fresh heparinized blood and mixed with a suspension of Rho cells $\left(0.8-1.0 \times 10^{6}\right)$ in PBS. The mixture was centrifuged at $160 \times g$ for $10 \mathrm{~min}$, the supernatant aspirated and polyethylene glycol 2000 solution in Hanks balanced salt solution was added to facilitate the cellular fusion. After $1 \mathrm{~min}$ incubation at $37^{\circ} \mathrm{C}$, the cell/platelet mixture was diluted to a final volume of $10 \mathrm{ml}$ with RPMI-1640 medium, centrifuged for $5 \mathrm{~min}$ at $150 \times g$ and resuspended in RPMI supplemented with $10 \%$ heat-inactivated FBS (lacking pyruvate and uridine). In these conditions, cybrids containing exogenous platelet mtDNA were selected. Surviving cybrid cells were analyzed for mtDNA content by real-time PCR.

Transient transfections. Transient transfections with DNp85, a dominant negative form of $\mathrm{PI} 3 \mathrm{~K}^{15,16}$ or empty vector (pcDNA3; Invitrogen) were performed as described earlier. ${ }^{15}$ Akt1, Akt2 and Akt3 siRNAs were purchased from Santa Cruz Biotechnologies and used for transient transfections according to the manufacturer's instructions. Negative control (nonspecific) siRNA (Santa Cruz Biotechnologies) was also transfected. SiRNA-mediated suppression of Akt1, Akt2 and Akt3 expression was confirmed by western blotting analysis.

Assays for intracellular glucose, extracellular lactate and cytochrome oxidase (Cox) activity. Glucose content and lactate production were assayed by a substituting medium containing $1.25 \mathrm{mg} / \mathrm{ml}$ glucose $24 \mathrm{~h}$ after transfection with Akt2 siRNA or nonspecific siRNA. After $24 \mathrm{~h}$, the conditioned medium was collected for lactate measurement using a standard lactate dehydrogenase enzymatic reaction, whereas adherent cells were washed two times with cold PBS, lysed with deionized $\mathrm{H}_{2} \mathrm{O}$ for $5 \mathrm{~min}$ on ice, and glucose content was measured with a commercially available kit (Sigma) according to the instructions by the manufacturer. Cox activity in mitochondrial isolates was determined as described by Amuthan et al. ${ }^{7}$
Immunohistochemical study. The construction of anonymized human prostatic tissue microarrays was approved by the University of Rochester's Research Subjects Review Board and has been described earlier. ${ }^{30}$ Briefly, archival prostatectomy cases in the Department of Pathology at the University of Rochester Medical Center were reviewed and 80 cases selected. One or more cores were taken from areas of normal prostatic tissue ( $N, 50$ cores), benign prostatic hyperplasia (BPH, 82 cores), high-grade prostatic intraepithelial neoplasia (PIN, 35 cores), low-grade adenocarcinoma (LGCA; Gleason grades 2 and 3, 104 cores) and high-grade adenocarcinoma (HGCA; Gleason grades 4 and 5, 82 cores), averaging four to six cores per case. Array blocks containing formalin-fixed, paraffinembedded core samples were sectioned at $5 \mu \mathrm{m}$ thickness, deparaffinized and quenched with $3 \%$ hydrogen peroxide for $6 \mathrm{~min}$. They were then cleared in running water followed by Tris-buffered solution (TBS), steamed in citrate buffer ( $\mathrm{pH} \mathrm{6.1}$ Dako, Glostrup, Denmark) at $95-99^{\circ} \mathrm{C}$ for $30 \mathrm{~min}$ and cooled for $15 \mathrm{~min}$. After rinsing with TBS, mouse monoclonal anti-human Cox I antibody (Molecular Probes) at a dilution of $1: 5000$ was reacted for $60 \mathrm{~min}$ at room temperature, followed by 30 min each incubation of biotinylated secondary antibody and a streptavidin-bound peroxidase enzyme complex. Slides were developed with AEC + (Dako) for $10 \mathrm{~min}$, rinsed in running distilled water, counterstained in Modified Mayer's Hematoxylin, stained blue in $0.3 \%$ ammonia water and viewed under a light microscope. Each core was separately scored and those having less than $50 \%$ of tissue present were discarded. Scoring included percentage of staining and staining intensity $(0,1+, 2+, 3+)$. Results were recorded as positive ( $5 \%$ or more, $1+$ to $3+)$ or negative $(<5 \%$ staining or staining intensity 0$)$. Paraffin-embedded sections of human kidney and placenta (red blood cells) provided the positive and negative control for Cox I staining, respectively.

Statistical analysis. Data are reported as the mean \pm S.E. Statistical analysis was performed using the Student's $t$-test. For the immunohistochemical study, Fisher's exact test and Mann-Whitney test were used to compare the statistical significance of the staining results among different groups, with similar results. $P$-values $<0.05$ were considered statistically significant.

Acknowledgements. We thank Patricia Bourne for technical assistance in immunohistochemical analysis. This work was supported by the MIUR-Contributi Straordinari di ricerca/aree obiettivo 1 grant (to EM) and by the CNR-Short-term Mobility Program 2006 (to LM).

1. Dakubo GD, Parr RL, Costello LC, Franklin RB, Thayer RE. Altered metabolism and mitochondrial genome in prostate cancer. J Clin Pathol 2006; 59: 10-16.

2. Petros JA, Baumann AK, Ruiz-Pesini E, Amin MB, Sun CQ, Hall J et al. mtDNA mutations increase tumorigenicity in prostate cancer. Proc Natl Acad Sci USA 2005; 102: 719-724.

3. Parr RL, Dakubo GD, Crandall KA, Maki J, Reguly B, Aguirre A et al. Somatic mitochondria DNA mutations in prostate cancer and normal appearing adjacent glands in comparison to age-matched prostate samples without malignant histology. J Mol Diagn 2006; 8: 312-319.

4. Booker LM, Habermacher GM, Jessie BC, Sun QC, Baumann AK, Amin M et al. North American white mitochondrial haplogroups in prostate and renal cancer. J Urol 2006; 175 468-472.

5. Nass MM. Differential effects of ethidium bromide on mitochondrial and nuclear DNA synthesis in vivo in cultured mammalian cells. Exp Cell Res 1972; 72: 211-222.

6. Amuthan G, Biswas G, Zhang SY, Klein-Szanto A, Vijayasarathy C, Avadhani NG Mitochondria-to-nucleus stress signaling induces phenotypic changes, tumor progression and cell invasion. EMBO J 2001; 20: 1910-1920

7. Amuthan G, Biswas G, Ananadatheerthavarada HK, Vijayasarathy C, Shephard HM, Avadhani NG. Mitochondrial stress-induced calcium signaling, phenotypic changes and invasive behavior in human lung carcinoma A549 cells. Oncogene 2002; 21: 7839-7849.

8. Higuchi M, Kudo T, Suzuki S, Evans TT, Sasaki R, Wada $Y$ et al. Mitochondria DNA determines androgen dependence in prostate cancer cell lines. Oncogene 2006; 25 1437-1445.

9. Moro L, Arbini AA, Marra E, Greco M. Mitochondrial DNA depletion reduces PARP-1 levels and promotes progression of the neoplastic phenotype in prostate carcinoma. Cell Oncol 2008; 30: 307-322.

10. Frisch SM, Francis $\mathrm{H}$. Disruption of epithelial cell-matrix interactions induces apoptosis J Cell Biol 1994; 124: 619-626.

11. Rennebeck G, Martelli M, Kyprianou N. Anoikis and survival connections in the tumor microenvironment: is there a role in prostate cancer metastasis? Cancer Res 2005; 65 11230-11235.

12. Ropiquet F, Berthon P, Villette JM, Le Brun G, Maitland NJ, Cussenot $O$ et al. Constitutive expression of FGF2/bFGF in non-tumorigenic human prostatic epithelial cells results in the acquisition of a partial neoplastic phenotype. Int J Cancer 1997; 72: 543-547. 
13. Mitchell S, Abel P, Ware M, Stamp G, Lalani E. Phenotypic and genotypic characterization of commonly used human prostatic cell lines. BJU Int 2000; 85: 932-944.

14. Moro L, Perlino E, Marra E, Languino LR, Greco M. Regulation of beta1C and beta1A integrin expression in prostate carcinoma cells. J Biol Chem 2004; 279: 1692-1702.

15. Moro L, Arbini AA, Marra E, Greco M. Down-regulation of BRCA2 expression by collagen type I promotes prostate cancer cell proliferation. J Biol Chem 2005; 280: 22482-22491.

16. Moro L, Arbini AA, Marra E, Greco M. Up-regulation of Skp2 after prostate cancer cell adhesion to basement membranes results in BRCA2 degradation and cell proliferation. J Biol Chem 2006; 281: 22100-22107.

17. Biswas G, Adebanjo OA, Freedman BD, Anandatheerthavarada HK, Vijayasarathy C, Zaid $\mathrm{M}$ et al. Retrograde $\mathrm{Ca} 2+$ signaling in $\mathrm{C} 2 \mathrm{C} 12$ skeletal myocytes in response to mitochondrial genetic and metabolic stress: a novel mode of inter-organelle crosstalk. EMBO J 1999; 18: 522-533.

18. Manning BD, Cantley LC. AKT/PKB signaling: navigating downstream. Cell 2007; 129 : 1261-1274.

19. Yakes FM, Van Houten B. Mitochondrial DNA damage is more extensive and persists longer than nuclear DNA damage in human cells following oxidative stress. Proc Natl Acad Sci USA 1997; 94: 514-519.

20. Ballinger SW, Patterson C, Yan CN, Doan R, Burow DL, Young CG et al. Hydrogen peroxide- and peroxynitrite-induced mitochondrial DNA damage and dysfunction in vascular endothelial and smooth muscle cells. Circ Res 2000; 86: 960-966.

21. Taanman JW, Bodnar AG, Cooper JM, Morris AA, Clayton PT, Leonard JV et al. Molecular mechanisms in mitochondrial DNA depletion syndrome. Hum Mol Genet 1997; 6: 935-942.

22. Van Huyen JP, Batisse D, Heudes D, Belair MF, Piketty C, Gonzalez-Canali G et al Alteration of cytochrome oxidase subunit I labeling is associated with severe mitochondriopathy in NRTI-related hepatotoxicity in HIV patients. Mod Pathol 2006; 19 1277-1288

23. Brandon M, Baldi P, Wallace DC. Mitochondrial mutations in cancer. Oncogene 2006; 25 4647-4662.

24. Higuchi M. Regulation of mitochondrial DNA content and cancer. Mitochondrion 2007; 7 53-57.

25. Pelicano H, Xu RH, Du M, Feng L, Sasaki R, Carew JS et al. Mitochondrial respiration defects in cancer cells cause activation of Akt survival pathway through a redox-mediated mechanism. J Cell Biol 2006; 175: 913-923.

26. Shaw $\mathrm{M}$, Cohen $\mathrm{P}$, Alessi DR. The activation of protein kinase $\mathrm{B}$ by $\mathrm{H} 2 \mathrm{O} 2$ or heat shock is mediated by phosphoinositide 3-kinase and not by mitogen-activated protein kinaseactivated protein kinase-2. Biochem J 1998; 336: 241-246.

27. Thomas SR, Chen K, Keaney JF. Hydrogen peroxide activates endothelial nitric-oxide synthase through coordinated phosphorylation and dephosphorylation via a phosphoinositide 3-kinase-dependent signaling pathway. J Biol Chem 2002; 277 : 6017-6024.

28. Mehdi MZ, Pandey NR, Pandey SK, Srivastava AK. H2O2-induced phosphorylation of ERK1/2 and PKB requires tyrosine kinase activity of insulin receptor and c-Src. Antioxid Redox Signal 2005; 7: 1014-1020.

29. Shukla S, Maclennan GT, Hartman DJ, Fu P, Resnick MI, Gupta S. Activation of PI3K-Akt signaling pathway promotes prostate cancer cell invasion. Int J Cancer 2007; 121: 1424-1432.

30. Moro L, Arbini AA, Yao JL, di Sant'Agnese PA, Marra E, Greco M. Loss of BRCA2 promotes prostate cancer cell invasion through up-regulation of matrix metalloproteinase9. Cancer Sci 2008; 99: 553-563.

31. Irie HY, Pearline RV, Grueneberg D, Hsia M, Ravichandran P, Kothari $\mathrm{N}$ et al. Distinct roles of Akt1 and Akt2 in regulating cell migration and epithelial-mesenchymal transition. J Cell Biol 2005; 171: 1023-1034.

32. Zhou GL, Tucker DF, Bae SS, Bhatheja K, Birnbaum MJ, Field J. Opposing roles for Akt1 and Akt2 in Rac/Pak signaling and cell migration. J Biol Chem 2006; 281: 36443-36453.

33. Biro S, Fu YM, Yu ZX, Epstein SE. Inhibitory effects of antisense oligodeoxynucleotides targeting c-myc mRNA on smooth muscle cell proliferation and migration. Proc Natl Acad Sci USA 1993; 90: 654-658.

34. Kim SD, Yang SI, Kim HC, Shin CY, Ko KH. Inhibition of GSK-3beta mediates expression of MMP-9 through ERK1/2 activation and translocation of NF-kappaB in rat primary astrocyte. Brain Res 2007; 1186: 12-20.

35. Zhou BP, Liao Y, Xia W, Zou Y, Spohn B, Hung MC. HER-2/neu induces p53 ubiquitination via Akt-mediated MDM2 phosphorylation. Nat Cell Biol 2001; 3: 973-982.

36. Rathmell JC, Fox CJ, Plas DR, Hammerman PS, Cinalli RM, Thompson CB. Akt-directed glucose metabolism can prevent Bax conformation change and promote growth factorindependent survival. Mol Cell Biol 2003; 23: 7315-7328.

37. Whang YE, WuX, Suzuki H, Reiter RE, Tran C, Vessella RL et al. Inactivation of the tumor suppressor PTEN/MMAC1 in advanced human prostate cancer through loss of expression. Proc Natl Acad Sci USA 1998; 95: 5246-5250.

38. Herrmann PC, Gillespie JW, Charboneau L, Bichsel VE, Paweletz CP, Calvert VS et al. Mitochondrial proteome: altered cytochrome $\mathrm{C}$ oxidase subunit levels in prostate cancer. Proteomics 2003; 3: 1801-1810.

39. Abril J, de Heredia ML, Gonzalez L, Cleries R, Nadal M, Condom E et al. Altered expression of 12S/MT-RNR1, MT-CO2/COX2, and MT-ATP6 mitochondrial genes in prostate cancer. Prostate 2008; 68: 1086-1096.

40. Singh KK, Kulawiec M, Still I, Desouki MM, Geradts J, Matsui S. Inter-genomic cross talk between mitochondria and the nucleus plays an important role in tumorigenesis. Gene 2005; 354: 140-146. 